\title{
Nurses' Motivators to Work Part-Time
}

\author{
Lynn N. Jamieson RN, PhD, Central Queensland Health Service District, Queensland \\ Leonie Mosel Williams RN, PhD, Faculty of Science, Health and Education, University of the Sunshine Coast, Queensland \\ William Lauder RN, PhD, School of Nursing and Midwifery, University of Dundee, Scotland \\ Trudy Dwyer RN, PhD, Faculty of Sciences, Engineering and Health, Central Queensland University, Queensland
}

There has been a trend of growth in part-time employment within the Australian nursing workforce and currently half of the profession work part-time. While the literature across disciplines has postulated reasons behind preferences for part-time employment, little is known about nurses' motivators to work part-time. In an era of nursing shortages that form considerable barriers to meeting healthcare service demands, a clear understanding of these motivators is critical for the effective planning and management of the nursing workforce. A grounded theory study that explored the phenomenon of part-time nursing found that nurses' motivators to work part-time were complex and identifiable with nursing, establishing that nurses' working time decisions are made in contexts that may be unique to the profession. This paper provides an exhaustive description and explanation of one cohort of part-time nurses that accounts for variations between nurses and provides an understanding of the complexity of factors that contribute to nurses' decisions to work part-time.

Key Words: nursing workforce; part-time employment; motivators; shift work; multiple roles.

Acknowledgements: This research study was supported financially by a Queensland Nursing Council scholarship and the Queensland Nurses' Union Moira Moffett Prize.
Correspondence to:

Dr Lynn Jamieson

E-mail: Lynn_Jamieson@heatth.qld.gov.au

\section{Introduction}

The numbers of Australian nurses in part-time employment have been increasing and approximately half of the profession currently work part-time (Australian Institute of Health and Welfare [AIHW], 2005). This is an important trend against a background where contemporary nursing shortages challenge the needs of healthcare service demand. The literature across disciplines suggests that part-time employment is a means to enable women to work while continuing to meet domestic commitments (Hakim, 1996a, 1996b, 1998; Newell, 1992; Pocock, 2003). As the nursing profession is predominantly female, it could be assumed that this is also the rationale for the increasing numbers of nurses working part-time (AIHW, 2005).

A number of authors have argued that part-time workers are a heterogenous group and to assume that all are alike is overly simplistic (Armstrong-Stassen, Al-Ma'aitah, Cameron, \& Horsburgh, 1998; Barling \& Gallagher, 1996; Hakim, 1998; Thorsteinson, 2003; Walsh, 1999). Walsh (1999) contends that there has been a shortage of evidence relating to the motivators to work part-time. Evidence in the literature suggests that knowledge of nurses' motivation to work part-time is limited with a significant lack of Australian-based knowledge.

Hawksworth (1999), a Queensland nursing union representative proposed that a detailed analysis was needed of the causes behind the increasing percentage of nurses working part-time. Hawksworth (1999) used anecdotal evidence to suggest that although nurses 'prefer' to work part-time because of family responsibilities, there may also be a lack of family friendly employment practices, pressure upon full-time employees to contribute to administrative functions out of work hours and a degree of work intensification that were contributing to nurses seeking part-time employment. Rather than relying on assumption and anecdote, the current and predicted future environment of nursing shortage provides a compelling impetus to develop a clearer and more accurate insight into nurses' motivators to work part-time. 


\section{Research design}

The findings reported in this paper emanare from a broader grounded theory study exploring the phenomenon of part-time nursing. Grounded theory methodology allows exploration into phenomena where little knowledge exists and it is recognised to be well-matched to nursing research (Lomborg \& Kirkevold, 2003; MacDonald \& Schreiber, 2001; McCann \& Clark, 2003; Schreiber, 2001; Smith \& Biley, 1997). The conduct of this study was based upon Strauss and Corbin's (1998) grounded theory approach. To provide clarity in this article 'part-time' employment is defined as being permanently contracted to work a fixed number of hours of less than thirty five hours per week and consisting of the same industrial conditions (pro rata for hours of employment) as for full-time employment. Based on this definition, nurses employed on a casual basis were not included. However, the findings may be relevant to nurses who work in casual employment.

\section{Sampling}

An initial use of purposive sampling was superseded by theoretical sampling (Coyne, 1997; Cutcliffe, 2000). Regional Queensland part-time nurses ( $\mathrm{n}=86)$ from five regional districts were the primary contributors of the data and the study attempted to draw part-time nurses representing a diversity of situations. Theoretical sampling drew part-time nurses from the public and private healthcare sectors, aged and residential care, mental health, community, private medical practice and acute care. Participants also varied in age, gender, their responsibility for dependents, years of nursing experience, employment position level, employment hours and nursing qualifications.

\section{Data collection}

Grounded theory has emerged from symbolic interactionism and in keeping with the methodology interviews became the prime source of data for this study (Annells, 1996; Backman \& Kyngas, 1999; Schreiber, 2001). Data was collected through individual and four focus group ( $\mathrm{n}=5+5+4+4)$ interviews. The initial use of unstructured interviews followed by semistructured interviews in line with study progression wisk consistent with the grounded theory approach (Duffy, Fergusis! \& Watson, 2004). Each interview contributed data to thir broader grounded theory study. This article reports data draw।I from the question that was used at the commencement of ill interviews, 'Can you tell me what led you to work part-time?'. $\wedge$ limited volume of relevant literature also contributed to data anil was included to broaden the richness of discovery.

\section{Data analysis}

All audio-taped interviews were transcribed verbatim and wers audited for quality of transcription. Memo writing and the constant comparative analysis technique were consistently used. Analysis followed a process of open, axial and selective coding, is suggested by Strauss and Corbin (1998). The analysis process wils achieved manually using the sorting facilities of QRS NUD*IS"I Vivo (NVivo) software. The cyclic process of theoretical sampling, data collection and analysis continued until data saturation wis: achieved.

\section{Ethical considerations}

The larger study was conducted as the primary component towards a doctoral degree. Prior to commencement of the study approval was gained from the University Human Ethics Research Review Panel. Access to potential participants was gained through approval from ethics committees at the recruitment sites. Signed informed consent was gained prior to data collection.

\section{Results}

The analytic process supported the category 'motivators to work part-time' to be conceptually developed. Concepts signifying properties are reported subordinate to the category and the concepts placed subordinate to these properties specify the dimensions of each property. Figure 1 is a visual model that acts as a 'roadmap'

\section{Figure 1: Motivators to work part-times}

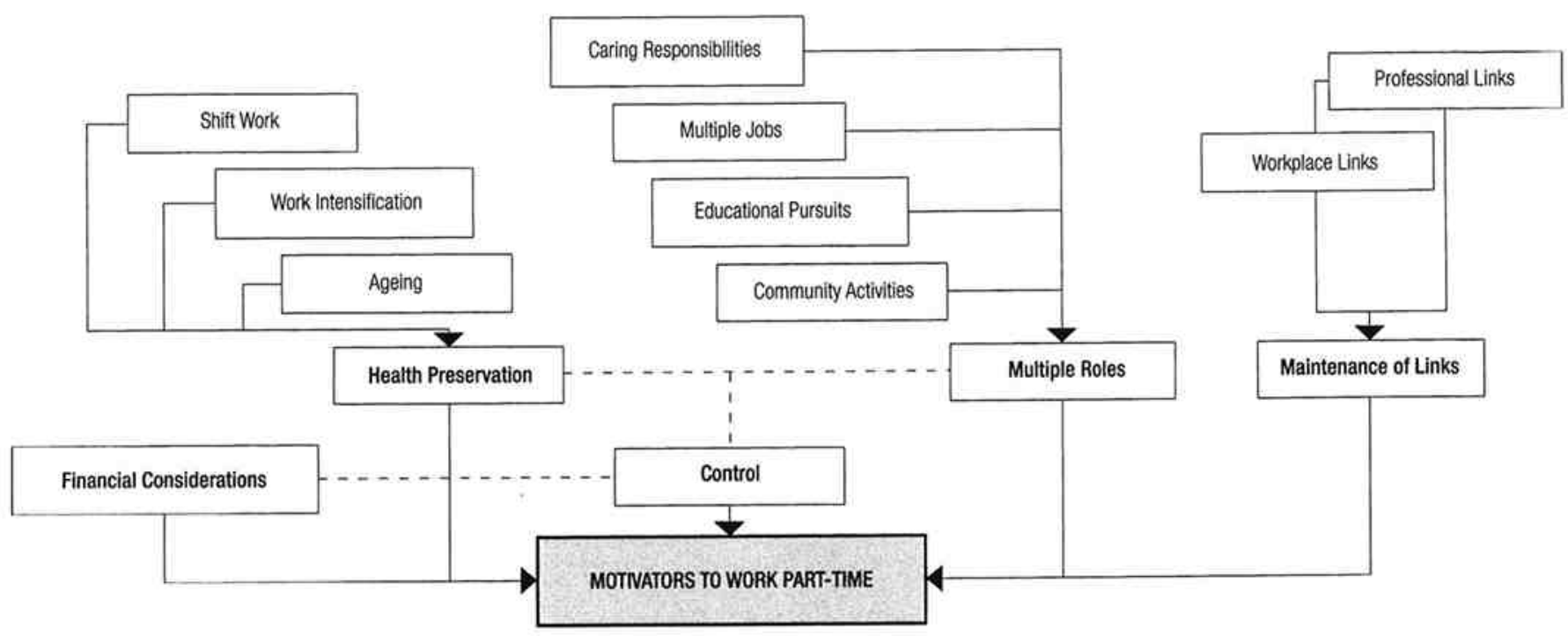


for this narrative report. The following study findings represent the concepts that developed from data.

In many instances several motivators were found to be associated with the decision to work part-time and these were frequently interrelated with varying degrees of personal priority given for each relevant motivator. Participants commonly perceived that motivators to work part-time would change over time. When asked if they would increase their employment hours in the future, data indicated that intention to permanently increase employment hours to full-time in the future was unlikely.

\section{Financial considerations}

The financial benefits of employment are clear and are commonly assumed to be a motivator to any employment. However, other primary motivators to part-time employment were presented in data and financial factors were rarely mentioned spontaneously. Exploration identified that financial factors were an issue that had been given prior thought by participants mainly in regards to the financial repercussions of forfeited income of part-time employment. A typical response was:

And I think we also know that money is not that different between working 8 shifts [a fortnight] and full-time. You get two days off extra and you're only $\$ 100$ out of pocket. I can live with $\$ 100$ out of pocket if I can have those two extra days off a fortnight.

Data proposed that the potential financial shortfall could be limited by salary sacrificing, rostering to penalty rate shifts that are outside of standard business hours, and because of adjusted tax schedules. The literature contribured data from a qualitative survey of the readership of the 'Nursing' journal. These data identified that financial considerations were also an issue for North American part-time nurses who suggested that associated financial deficits were able to be limited through adjusting work schedules and personal spending (Godfrey, 1980).

In the current study financial considerations influenced decisions related to the number of hours participants were willing to work. Financial demands were perceived to be constant and transitory. For example, constant demands were met through contracted employment hours and transitory financial demands were met by working a second job or by working hours beyond contracted hours:

$$
\begin{aligned}
& \text { And I manage financially on part-time. I can always pick up extra shifts } \\
& \text { if I want it and I do when I need the money. }
\end{aligned}
$$

linn:uncial considerations were associated with motivators to parttime employment but were not the primary motivator.

\section{Health Preservation}

Shilit work, work intensification and ageing and the impract of

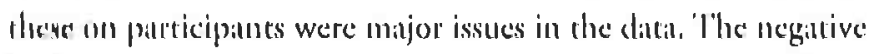
leceld innpaces were found to independently and collectively be

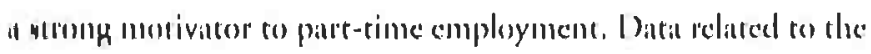

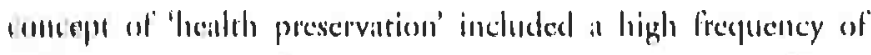
oxprenaloum such as 'burn/t ont', 'morn ont' and 'killer'. 'l'hesce

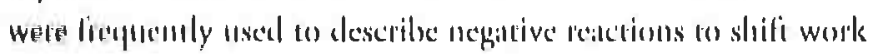

and work intensification. Idioms such as 'breathing space', 'refresh' and 'recharging batteries' were commonly cited by participants to identify how part-time employment positively assisted to offset these negative reactions. The following comment is an example:

... for me personally, working part-time the benefits are that I've got some

breathing space, so I'm refreshed, I'm not worn out, I'm not burnt out...

Analysis of all data identified that this concept was a primary motivator for some participants to work in part-time employment while for others it represented a secondary motivator.

\section{Shift work}

Part-time employment was suggested to be more appealing than full-time employment when work schedules included shift work:

... part-time, it doesn't make me sick, I can sleep more... if you're working 40 hours or more than 40 hours it's just too much physicallys emotionally, you break down. The shift work, the night duty, you can't physically maintain that lifestyle for 40 hours in a week; I don't think it's possible without being sick...

Of primary concern was the inability to deal with the health effects of night shifts. Shift work was perceived as conflicting not only with physical health but with emotional and social or relationship wellbeing:

It [shift work] affects me physically, probably the lack of sleep, sleep deprivation... It's very tiring and I can't cope emotionally.

... shift work is a social killer as far as your social life is concerned.

It was just very difficult working shift work and we were trying to bave a child... and eventually our marriage broke up...

The literature contributed data from a qualitative study of married North Americans that found that shift work reduced marital quality and increased divorce potential (White \& Keith, 1990).

Healthcare environments that provided twenty four hour nursing services through a three shift per day rostering schedule were of concern to participants; a concern shared by the International Council of Nurses [ICN] (2000). In the current study rostering schedules that included regularly working all three shifts were perceived to negatively affect health:

... to work a latelearly [shifts] and to come home and basically sometimes
get only two or three hours sleep because your mind is racing from
working the late. And then having to get up and do the early. The way
you feel when you get home at four in the afternoon on the day after the
latelearly, that's not healthy...and then of course you have to front up for
a night [shift] the next day...

Data from a substantial literature related to the negative outcomes that nurses experience from working shift work contributed to participants' data (Brooks, 2000; Fitzpatrick, While \& Roberts, 1999; Jamal \& Baba, 1992; Poissonnct \& Véron, 2000; Totterdell, Spelten, Sinith, Batton \& Folkard, 1995). British author Brooks (200(0)), in a metit-innalysis of empirical studies related to flexible work arr:ungements, found that compulsion to work shifts that are nor canducive to the individual such as night shifts and rotiting shifts led to increased health problems. The Australian report titled the patient profession: Time for action. Report on the inquiry into nursing (Commonwealth of Australia, 2002) suggested that shift work is unattractive to many nurses and should no longer be accepted as an inevitability of working as 
a nurse. Wilson's (2002) literature review into shift work for healthcare personnel found that individual preference and control were important issues to those working shift work. Parttime employment was perceived as an avenue to work less shift work than would be worked in full-time employment and therefore provided a means to maintain health.

\section{Work intensification}

Data regularly described high levels of work intensification and this was presented as a secondary motivator to work in part-time employment. The Australian report mentioned previously (Commonwealth of Australia, 2002) proposed that nurses have to meet high levels of need, technology and fast admission and discharge flows. Data from other literature identified that work intensification is an issue for contemporary Queensland nurses (Hegney, Plank \& Parker, 2003). Additionally, increasing nursing shortages have been linked with escalating nursing work intensity in Australia (Queensland Nurses' Union, 2001, 2002; Wickett, McCutcheon \& Long, 2003).

Contemporary nursing was commonly perceived as physically intense:

... the ward is at its most stressful as in its busiest or most demanding...

in actual fact I find that I go home physically tired... I mean my feet sing

from all the walking...

Intellectual intensification of nursing work was also of concern:

... I think that in the acute care situation, specifically where I am, it's more mental than physical and you often come home mentally wiped out after a shift.

Analysis identified that it was the combination of these factors that led to perceptions that nursing was practiced in a milieu of high work intensification.

Commonly the effects of work intensification were not confined to the work environment but pursued participants at home. The literature contributed data from a Swedish study that found evidence that work related issues remained with nurses when they were at home (Olofsson, Bengtsson \& Brink, 2003). Participants in the current study perceived that work intensity made nursing a 'threat' to them as it could 'take over your life'. These idioms were related a number of times in response to this issue. Part-time employment was proposed to enable a reduction of the threat to participants. An example of respondents' comments follows:

Well [with part-time employment] you can actually get work space out of your head. You have more time to focus on other areas of your life... so you're not... having all your days off and still baving work stuff going through your head...

\section{Ageing}

The concept of ageing was not a singular concept, in the data. Rather it was integrally connected to the 'shift 'work' and 'work intensification' concepts. Ageing was suggested to be closely correlated to the negative health outcomes associated with shift work and work intensification:

Yon get tired... but I think it's worse when you get older.
The literature has also established that aging increases shift work intolerance (Brooks, 2000; Poissonnet \& Véron, 2000). In the current study chronic work induced health factors and transition to retirement also became motivators to part-time employment associated with aging. Additionally, the concept of ageing was perceived by many as a significant future motivator to part-time employment.

\section{Multiple Roles}

Participants described their many life roles as motivating them to work part-time. These multiple roles were considered to be important and a primary rationale for seeking part-time employment. Analysis of all data relating to multiple roles identified that although specific roles provided the explicit motivation to work part-time, it was the combination of multiple roles with associated accumulated demands that impacted on participants' working time decisions. Demands were significantly increased where multiple roles existed and this impacted considerably on decisions related to the hours that could be devoted to employment. A typical comment was:

I've got full-time life work and part-time employment and five years ago it was the other way around... The other day we were discussing if I should take on the role of secretary of the... [sports] club... And be [husband] said 'Well you've got a lot on but you could probably cope with it because you're not working a lot'. And I said 'Excuse me, not working much! Right, so I'll stop mowing the lawn, washing up, getting lunches ready, dropping... [older child] off at preschool, looking after... [younger child], doing the [business] books for you, ironing your clothes, looking after your mother, doing her shopping twice a week, washing her clothes, and that is just a few of the things that I do. Did you say that I'm not working much?' But you know Lynn, I am now the secretary of the... [sports] club.

Grosswald (2003), reporting findings from a North American workforce survey, suggested that time spent in the workplace implied time away from other roles. There is a wealth of literature dealing with the three major models related to the worklife (or work-family) phenomenon: the 'compensation theory' presumes that work and life are complementary; the 'spillover theory' surmises that there is a transfer of negative or positive factors from one domain to the other; and the 'conflict theory' posits that work and life compete for available resources (Greenhaus \& Beutell, 1985; Grosswald, 2003; Jansen, Kant, Kristensen \& Nijhuis, 2003; Thomas \& Ganster, 1995). In the current study data suggested that part-time employment enables work-life compensation to occur. Negative work-life and lifework spillover and conflict were associated with full-time employment. The following comment was typical:

... the benefits to me [of part-time work] is that because I get more time off I feel more settled in my home life. So of course that makes you more settled at work. You're not constantly stressed out; you're not bringing problems to and fro from work to home and visa versa. That's the biggest advantage to myself because I did find that I was becoming quite stressed out and you don't realise how stressed you actually are until you drop the days [worked].

The potential for negative spillover or conflict strengthened motivations to work in part-time employment. 


\section{Caring responsibilities}

Responsibility for dependants was the chief motivator found in data for the decision to work part-time. There is a plethora of literature beyond nursing establishing that part-time employment is a means used to enable women to participate in the workforce while continuing to meet traditional domestic commitments (Hakim, 1996a, 1996b, 1998; Newell, 1992; Pocock, 2003). The foci of caring motivations in the current study were related to dependant children as opposed to aged dependants, this rationale submerged in the fact that no participant had aged dependants living with them. Full-time employment prior to having children was followed by part-time employment after the first child's birth. Changing to part-time employment after having children was perceived as a 'normal' thing to do. There was the suggestion that societal norms also influenced these working time decisions:

... when I decided to drop from full-time to part-time it was like a chronological thing that people did. It's the norm, you get married and you have your first child and you drop back [hours worked]. So a natural progression I suppose.

Data, as in the following excerpt, established that it was family needs that impacted most on working time decisions:

You know it's funny, before I bad children I was definitely quite career orientated... But it's funny since having the kids, things come at a cost, and I do find it hard to balance work and home. And so unfortunately it's work that's going to give because of the kids. They're always going to be the priority.

Household domestic work was presented as part of caring responsibilities. Division of household domestic work commonly followed traditional gendered distributions. This appeared to occur irrespective of division of responsibilities for paid work ourside the home:

... for a period after having a family my husband was the home person for a while and I worked full-time... It was very difficult... he wasn't doing the roles that I normally take care of in the home. So therefore I was working full-time as well as holding down all the bome jobs as well. So it was a stressful situation...

Suitable access to formal child care providers was seen as problematic and a source of significant stress to the participants. This comment exemplifies the stories of many others:-

I can't have a day care centre, there is minimal care in the community for shift workers' [children]... Day care centres don't even open before $7 \mathrm{am}$ in the morning and I think they shut at 6pm. So you need other people. I've had the situation where my children have changed hands up to three different people for my one shift... There's not enough spaces with the one day care mother. So, one of my children actually goes to two other day care mothers... It's a nightmare.

The Australian general and nursing based literature confirms that child care is a considerable concern for working parents (Commonwealth of Australia, 2002; Pocock, 2003; Queensland Health, 1999; Queensland Nurses' Union, 2002; Thornthwaite, 2002). The current study identified that shift work and inflexible rostering exacerbated the difficulties of accessing formal child care providers. Caring responsibilities were analysed (n) be the chief motivator to part-time employment.

\section{Multiple jobs}

A notable percentage of participants (29\%) were employed in more than one job. International studies exploring part-time nursing also established that a considerable percentage of parttime nurses in other countries are working for more than one employer (Edwards \& Robinson, 2004; Garbett, 1996; Registered Nurses Association of Ontario [RNAO], 2003; Wetzel, Soloshy \& Gallagher, 1990). The literature provided several proposed rationales for this including that multiple jobs were used to offer variety in nursing work and that the mutuality of benefits between employee and single employer was incomplete (Edwards \& Robinson, 2004; RNAO, 2003).

A small number of second employment positions in the current study were associated with family businesses and not related to nursing. Additional nursing positions were most commonly through casual employment. Working in multiple jobs was not a common motivator in the data. Rather multiple jobs were used to diversify nursing experiences or to supplement income. However, these jobs represented yet more roles that were included in participants' repertoire of roles that in turn impacted on working time decisions.

\section{Educational pursuits}

Data suggested that part-time nursing provided some flexibility to enable attendance at informal educational forums:

... like if you want to fit one or two workshops in a year you go to it basically in your own time, because you've got more days off [than when working full-time]...

Studying towards post-registration qualifications was perceived as difficult if working full-time. One participant noted:

... And when I was studying too it was certainly a benefit to be working part-time... I don't know if I could have done it if I worked

full-time. It was certainly easier to do it working part-time.

The Queensland Nurses' Union (2001), in their submission to the senate inquiry into nursing, suggested that this is a problem that many Queensland nurses face.

\section{Community activities}

Community activities were commonly discussed by participants. These activities were wide ranging but frequently included socialising with friends, sporting commitments and membership in various community clubs and organisations:

I play squash... and I also belong to organisations such as Toastmasters... as well as having joined the voluntary workforce in such roles as the school tuckshop roster...

Varying degrees of priority were placed on community activities. However, analysis identified that community involvements were not a direct motivation to work in part-time employment. Nevertheless, there was significant evidence that these formed yet another concept that contributed to participants' multiple roles and as such were associated with motivation to participate in part-time employment. 


\section{Maintenance of Links}

Analysis found that part-time employment was used at times to maintain links with the profession and the workplace.

\section{Professional links}

A desire to maintain nursing knowledge and skills was a contributing motivator to part-time employment. When employed in other non-clinical nursing employment, maintenance of clinical nursing knowledge and skills was identified as a motivation that enabled professional credibility to be retained. Developing links with others in the profession was also a motivator. The literature also provided some evidence to support this as a motivator to part-time employment (Wetzel, Soloshy \& Gallagher, 1990).

\section{Workplace links}

Social and mental stimulation were proposed as secondary motivators to the decision to work part-time:

... I had six months off after both children and by the end... I was brain dead, like goo-goo-gaa-gaa... Whereas coming to work, yes it's great for me because I get to interact with other adults... and to keep the brain ticking over, to learn new skills..

Social stimulation was associated with relationships with clients and with workplace friends and colleagues. The nursing literature has identified that mental stimulation and companionship are motivators to return to nursing on a part-time basis (Khalil \& Davies, 2000; Robinson, Marsland, Murrells, Tingle \& Smith, n.d.). The literature also suggested that those who stay at home because of caring responsibilities have declining accessibility to social networks (Barnett \& Hyde, 2001). Pocock's (2003) analysis of the relationship between work and caring responsibilities that was based on multiple data sources found that Australian communities have shifted from the traditional neighbourhood street to the workplace, providing a basis for this trend.

\section{Control}

'Control' has been identified to be a discernible motivator to work part-time that was evident from many participants. The literature also identified that females in general and nurses more specifically choose to work part-time to gain 'control' (Brooks, 2000; Godfrey, 1980; Kemp, 1994; Pocock, 2001). Control was proposed as the perceived or real level of choice and influence that a nurse has in the decision making process affecting working time patterns (Brooks, 2000).

Participants were motivated to work in a part-time capacity so that they could control the dichotomising of available time by limiting the time spent in the workplace:

$I$ definitely see it [part-time employment] as more flexible for my personal life. I have more control over what I can do with my personal life if I'm part-time. I feel like if I was full-time then there would be five days a week that the choices of what I could do with my time outside work have been reduced, whereas at the moment it is only three days a week. Even if I get a bad roster..., then there's only three days that are ruined, not five out of my personal time. It's a control factor; it really is a control thing.
Analysis established that the motivator 'control' was a consequence of other motivators. Participants used part-time employment as a means to control imbalances so that a synergy could be built in relation to financial considerations, health and the multiple roles that each participant performed. The literature suggested that those who have higher levels of stressors and demands may be more likely to seek control (Brooks, 2000).

\section{Conclusion}

The findings of nurses' motivators to part-time employment provide a rich understanding of the complexity of working time decisions. It is unsurprising that caring responsibilities were the chief motivator for nurses' decisions to work part-time. However, the findings have confirmed that there is a greater complexity to motivators to work part-time rather than the narrow focus of caring responsibilities that is proposed in the literature. Many of the concepts that have been reported in this paper were identifiable with nursing, establishing that nurses' working time decisions are made in contexts that may be unique to the profession. This study's findings have clearly established that while current circumstances of shift work, work intensity and an aging workforce remain nurses will continue to choose part-time employment.

An exhaustive description and explanation of one cohort of nurses' motivators to work part-time has been provided. These findings account for variations between nurses and provide an understanding of the complexity of factors that contribute to nurses' decisions to work part-time. There is the suggestion that currently full-time nursing is perceived as a physical, emotional and social 'threat' to the individual nurse. The challenge that the Australian nursing profession and healthcare organisations face is to use this knowledge to develop strategies that reduce this threat. Stemming the increasing numbers of nurses who choose to work reduced hours of employment will in turn assist to relieve current nursing shortages.

\section{References}

Australian Institute of Health and Welfare, (2005). Nursing and midwifery labour force 2003, cat. no. HWL 31, Canberra: Australian Institute of Health and Welfare. Annells, M. (1996). Grounded theory method: Philosophical perspectives, paradigm of inquiry, and postmodernism. Qualitative Health Research, 6(3), 379-393.

Armstrong-Stassen, M., Al-Ma'aitah, R., Cameron, S. J., \& Horsburgh, M. E. (1998). The relationship between work status congruency and the job attitudes of full-time and part-time Canadian and Jordanian nurses. The Intemational Joumal of Human Resource Management, 9(1), 41-57.

Backman, K., \& Kyngas, H. A. (1999). Challenges of the grounded theory approach to a novice researcher. Nursing and Health Sciences, 1, 147-153.

Barling, F., \& Gallagher, D. G. (1996). Part-time employment. Review of industrial and Organizational Psychology, 11, 243-277.

Bamett, R. C., \& Hyde, J. S. (2001). Women, men, work, and family: An expansionist theory. American Psychologist, 56(10), 781-796.

Brooks, I. (2000). Nurse retention: Moderating the ill-effects of shift work. Humm Resource Management Joumal, 10(4), 16-31.

Commonwealth of Australia, (2002). The patient profession: Time for action. Reppoul on the inquiry into nursing. Retrieved from $\mathrm{http}: / /$ www.aph.gov.au/sennto/ cornmittee/clac_ctte/nursing/report/index.htm

Coyne, I. T. (1997). Sampling in qualitative research. Purposeful and tieoruttcitl sampling; merging or clear boundaries? Joumal of Advanced Nursing, 26, 6'? 


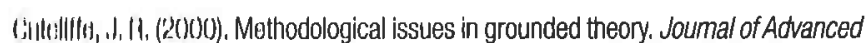
Nillillin, 31(0), 1476-1484.

IIIIly, K, lu|r(j|uson, C., \& Watson, H. (2004). Data collecting in grounded theoryituntu jrictical issues. Nurse Researcher, 11(4), 67-78.

I (Iwircls, C, Y, \& Robinson, 0. (2004). Evaluating the business case for part-time wurking anıongst qualified nurses. British Joumal of Industrial Relations, 42(1), 16/-183.

Iill/patrlck, J. M., While, A. E., \& Roberts, J. (1999). Shift work and its impact upon I Iurse performance: Current knowledge and research issues. Joumal of Advanced Nursing, 29(1), 18-27.

Garbelt, R. (1996). Speaking out. Nursing Times, 11(37), 52-53.

Godfrey, M. A. (1980). Is part-time nursing the answer for you? Part 1. Nursing, 10(10), 65-72.

Greenhaus, J. H., \& Beutell, N. J. (1985). Sources of conflict between work and family roles. Academy of Management Review, 10000001), 76-88.

Grosswald, B. (2003). Shift work and negative work-to-family spillover, Joumal of Sociology and Social Welfare, 394), 31-56.

Hakim, C. (1996a). Key issues in women's work: Female heterogeneity and polarisation of women's employment. London: Athlone.

Hakim, C. (1996b). The sexual division of labour and women's heterogeneity. The British Joumal of Sociology, 471), 178-188.

Hakim, C. (1998). Social change and innovation in the labour market. Melbourne: Oxford University Press.

Hawksworth, G. (1999). The nursing perspective. Retrieved from http://www.qnu.org.aw worktimelife.htm

Hegney, D., Plank, A., \& Parker, V. (2003). Nursing workloads: The results of a study of Queensland Nurses. Journal of Nursing Management, 11(5), 307-314.

International Council of Nurses, (2000). Nurses and shift work. Retrieved from http://www.icn.ch/psshiftwork00.htm

Jamal, M., \& Baba, V. V. (1992). Shiftwork and department-type related to job stress, work attitudes and behavioral intentions: A study of nurses. Journal of Organizational Behavior, 13, 449-464.

Jansen, N. W., Kant, I., Kristensen, T. S., \& Nijhuis, F. (2003). Antecedents and consequences of work-family conflict: A prospective cohort study. Journal of Occupational and Environmental Medicine, 45(5), 479-491.

Kemp, J. (1994). Career paths revisited: The experiences of graduates in nursing who no longer work full-time. Joumal of Advanced Nursing, 20, 377-381.

Khalil, A., \& Davies, N. (2000). The experiences of nurses returning to work after childbirth: 'Making a difference'. Joumal of Nursing Management, 866), 337-344.

Lomborg, K., \& Kirkevold, M. (2003). Truth and validity in grounded theory - a reconsidered realist interpretation of the criteria: Fit, work, relevance and modifiability. Nursing Philosophy, 4(3), 189-200.

MacDonald, M., \& Schreiber, R. S. (2001). Constructing and deconstructing: Grounded theory in a postmodern world. In R. S. Schreiber \& P. N. Stern (Eds.), Using grounded theory in nursing (pp. 35-53). New York: Springer.

McCann, T. V., \& Clark, E. (2003). Grounded theory in nursing research: Part 1 methodology. Nurse Researcher, 11(2), 7-18.

Newell, S. (1992). The myth and destructiveness of equal opportunities: The continued dominance of the mothering role. Personnel Review, 21(4), 37-47.
Olofsson, B., Bengtsson, C., \& Brink, E. (2003). Absence of response: A study of nurses' experience of stess in the workplace. Joumal of Nursing Management, 11(5), 351-358. Pocock, B. (2001). Having a life: Work, family, faimess and community in 2000. Retrieved from http:/hww.arts.adelaide.edu.au/socialinquiry/staff/pocock_bartara.htm Pocock, B. (2003). The work / life collision. Sydney: Federation Press.

Poissonnet, C. M., \& Véron, M. (2000). Health effects of work schedules in healthcare professions. Joumal of Clinical Nursing, 9(1), 13-23.

Queensland Health, (1999). Ministerial taskforce: Nursing recruitment \& retention. Retrieved from http://www.health.qld.gov.aw/publications/haw/qh_nrr.pdf

Queensland Nurses' Union, (2001). Summary of ONU recommendations: Senate inquiry into nursing 2001. Retrieved from http://www.aph.gov.au/Senate/ committee/eet_ctte/skills/submissions/sub015b.pdf

Queensland Nurses' Union, (2002). Submission by the Queensland Nurses' Union: Queensland Work and Family Taskforce 2002. Retrieved from the htt://www.qnu.org.au/_data/page/253/sub workfamily.pdf

Registered Nurses Association of Ontario, (2003). Survey of casual and part-time registered nurses in Ontario. Retrieved from http://www.rna0.org/html/PDF/ RNAO_part_time_casual_report.pdf

Robinson, S., Marsland, L., Murrells, T., Tingle, A., \& Smith, R. (n.d). Careers of registered general nurses. Combining work and family: Nurses' experiences four to eight years after qualification. Executive summary. Retrieved from http://www.kcl.ac.uk/nursing/nru/pdf/rgn//RGN\%20Exec\%20sum-final.pdf

Schreiber, R. S. (2001). The "how to" of grounded theory: Avoiding the pitfalls. In R. S. Schreiber \& P. N. Stern (Eds.), Using grounded theory in nursing (pp. 55-83). New York: Springer.

Smith, K., \& Biley, F. (1997). Understanding grounded theory: principles and evaluation. Nurse Researcher, 4, 17-30.

Strauss, A., \& Corbin, J. (1998). Basics of qualitative research: techniques and procedures for developing grounded theory (2nd ed.). London: Sage.

Thomas, L., \& Ganster, D. (1995). Impact of family-supportive work variables on work-family conflict and strain: A control perspective. Journal of Applied Psychology, 8Q(1), 6-15.

Thorsteinson, T. J. (2003). Job attitudes of part-time vs. full-time workers: A meta-analytic review. Joumal of Occupational and Organizational Psychology, 76(2), 151-177.

Thornthwaite, L. (2002). Work-family balance: Intemational research on employee preferences. Retrieved from http://www.acirrt.com

Totterdell, P., Spelten, E., Smith, L., Barton, J., \& Folkard, S. (1995). Recovery from work shifts: How long does it take? Journal of Applied Psychology, 80(1), 43-57.

Walsh, J. (1999). Myths and counter-myths: an analysis of part-time female employees and their orientations to work and working hours. Work, Employment \& Society, 13(2), 179-203.

Wetzel, K., Soloshy, D. E., \& Gallagher, D. G. (1990). The work attitudes of full-time and part-time registered nurses. Health Care Management Review, 15(3), 79-85.

White, L, \& Keith, B. (1990). The effect of shift work on the quality and stability of marital relations. Journal of Marriage and the Family, 52(2), 453-462.

Wickett, D., McCutcheon, H., \& Long, L. (2003). Commentary: An Australian perspective. Journal of Advanced Nursing, 43(4), 343-345.

Wilson, J. L. (2002). The impact of shift patterns on healthcare professionals. Joumal of Nursing Management, 1044), 211-219. 